\title{
Intranet Supported Knowledge Sharing Behavior
}

\author{
Mohamad Noorman Masrek, Hasnah Abdul Rahim, \\ Rusnah Johare and Yanti Rahayu Rambli
}

Universiti Teknologi MARA, Shah Alam, Malaysia

\begin{abstract}
While most corporate organizations in Malaysia have implemented intranet or portal, questions regarding users' utilization behavior for the purpose of knowledge sharing still remain unanswered. Against this concern, this study seeks to investigate demographic profiles associated with knowledge sharing behavior in an intranet computing environment in selected Malaysian companies. Using the survey research method, 700 questionnaires were distributed using the simple random sampling technique yielding to 359 usable responses. The findings suggest that there is a significant difference in terms of knowledge sharing behavior across demographic profiles. In addition, it was also found that both length of service and internet experience is a significant predictor of knowledge sharing behavior in an intranet computing environment.
\end{abstract}

Keywords: knowledge sharing, intranet, Malaysian companies

\section{Introduction}

Since its first inception a decade ago, the intranet has achieved major advancement and sophistication. At present, intranet technologies have significantly mature and they exist in all sizes, shapes, and forms. In fact, more sophisticated terms like intranet portal, enterprise portal, enterprise information portal or EIP (Shilakes and Tylman, 1998) have been coined to reflect the advancement and complexity of the technology. Hinrichs (1997) defined intranet as an internal IS based on internet technology, web services, TCP/IP and HTTP communication protocols, and HTML publishing that permits organization to define itself as a whole entity, a group, a family, where everyone knows their roles and everyone is working on the improvement and health of the organization.
Intranet, in its full functionalities can be used as a publishing application, discussion application and interactive application. Within the scope of discussion application, users can utilize the intranet technology for knowledge sharingpurposes. Today, while most corporate organizations in Malaysia are intensely implementing intranet or portal, questions regarding users' utilization behavior for the purpose of knowledge sharing still remain unanswered. Not much is really known about the extent Malaysian users utilize intranet technology for knowledge sharing purposes. Against this background, this study seeks answer the following research questions i.e. What are the demographic profiles associated with knowledge sharing behavior in an intranet computing environment? In addition, it also attempt to find answers to the following: (i) Is there any significant difference of 
knowledge sharing behavior between male and female? (ii) Is there any significant difference of knowledge sharing behavior among different age group of users? (iii) Is there any significant difference of knowledge sharing behavior between managers and non-managers? (iv)Does length or service significantly and positively relate to knowledge sharing behavior? and (iv) Does internet experience significantly and positively relate to knowledge sharing behavior?

\section{Literature Review}

\section{Intranet Background}

While the Internet started out from the ARPANET project in the late 1960s, intranets are the result of the growing number of companies beginning to run TCP/IP on their intra-organizational networks in the mid1990s (Slevin, 2000). Karlsbjerg and Damsgaard (2001) described intranet as "a shared information space that supports the sharing of information among members of an organization. The space comprised a number of technical standards and platforms interconnected in a network within welldefined boundaries of a group of people or computers. All communication goes through the web-browser using TCP/IP and HTTP protocols. Thus, any application can be part of the intranet as long as the browser is primary client interface". Intranets are also sometimes referred to as 'glueware' or 'middleware' since they are utilized to interconnect heterogeneous systems through the browser and associated protocols and applications (Lyntinen et al., 1998).

Looking from the IS perspectives, intranet technologies offer formidable benefits compared to traditional technologies which tend to only support well-defined tasks (Damgaards and Scheepers, 1999). These advantages include rapid scalable development across a range of platforms, access to legacy systems and data warehousing capabilities, and development on existing networks with lower implementation cost compared to traditional client server solutions (Golden and Hughes, 2001). In addition, the time taken for intranet implementation which includes design, development and implementation and enduser training is relatively much quicker than traditional solutions. Hence, the intranets are providing organizations with far more flexibility than traditional IS (Golden and Hughes, 2001).

\section{Intranet Usage for Knowledge Sharing}

Recognizing the importance of knowledge sharing, many organizations have deployed or exploited the intranet as part of their knowledge management initiative programs. The literature indicates that there exist diverse studies that specifically address the role of intranet in facilitating knowledge sharing (Newell et al., 1999; Ruppel and Harrington, 2001; Stoddart, 2001; Holden, 2003; Lichtenstein et al., 2004; Hall, 2004; Panteli et al., 2005; Stenmark, 2005c; Stenmark, 2005e). Other studies such as Scott (1998); Stenmark (1999a); Damsgaard and Scheepers (2001); Stenmark (2002); Sarkar and Bandyopadhyay (2002); Dingsoyr and Conradi (2003); and Skok and Kamanovitch (2005) not only addressed primarily the role of the intranet in supporting knowledge management initiatives but also stressed equal emphasis on knowledge sharing.

In order to best describe how the intranet can facilitate knowledge sharing, Stenmark (2002) and Lichtenstein et al., (2004) developed a model that describes intranet utilization for supporting knowledge management. Stenmark's model, suggests that the intranet as a knowledge sharing environment is seen from three perspectives: information, awareness and communication. The information perspective relates that the intranet gives the organizational members access to both structured and unstructured information in the form of databases and documents. Access to rich and diverse information is imperative for knowledge creation. The awareness perspective suggests 
that the intranet is used to keep users wellinformed and constantly connected to information and people in the organization. Such a networking practice promotes community building and increases the likelihood for successful communication and collaboration. The communication perspective enables organizational members to collectively interpret the available information by supporting various forms of channels for conversation and negotiations. When users engaged in collaborative work with peers that share their objectives and understand their vocabulary, the common context for knowledge sharing would then exist.

Lichtenstein et al., (2004) conceptualization of knowledge sharing mediated by the intranet exhibits a sharer who chooses to provide knowledge to be published, and provides that knowledge which is then published on the intranet. A potential receiver will search and find the required knowledge, retrieve it then relate it to his/her existing knowledge. The knowledge is then assimilated before it can be applied as required. The fact that the knowledge has been retrieved by the receiver, as well as response to that knowledge, is fed back to the sharer, whose future knowledge-sharing behavior may change accordingly.

\section{Individual Characteristics and Knowledge Sharing Behavior}

Every individual is subject to his own personal traits and to the environment or surrounding that he belongs to or is attached with. Theory of Diffusion of Innovation (Rogers, 1995) posited that besides individual beliefs of the innovation characteristics (i.e. the object or technology being studied) other factors such as individual characteristics, organizational characteristics and external characteristics are also influential in molding one's behavior associated with individual adoption behavior. Models such as Technology Acceptance Model (Davis et al., 1989) and Unified Theory of Acceptance and Use of Technology or
UTAUT (Venkatesh et al., 2003) have been consistently showed by researchers that individual characteristics, organizational characteristics and technology characteristics are predictors or antecedents of technology adoption (see Jeyaraj et al., 2006). A large number of studies on the intranet have attempted to investigate the effects of the individual characteristics, organizational characteristics and technology characteristics on intranet adoption. However, these studies either done at the firm-level perspective (Al-Gharbi and Atturki, 2001; Eder and Igbaria, 2001) or user-level perspective (Horton et al., 2001; Weitzel and Hallahan, 2003; Chang, 2004) were meant to determine use or non-use and not for knowledge sharing behavior. Furthermore, in the context of Malaysia, none has ever attempted to investigate knowledge sharing behavior in an intranet computing environment.

\section{Research Methodology}

The conduct of the study involved survey research method. Several companies with high intranet maturity (i.e. the intranet are being integrated with organizational information systems) were contacted to participate in the survey. However, only four companies were willing to participate in the study. After a lengthy discussion with the contact person of these companies, it was decided that the respondents of the study should be the executives in the headquarters only. The rationale being that, compared with the support staffs, the executives are the heavy users of the intranet. Accordingly, 700 questionnaires were administered to these participating companies using stratified random sampling. After one-month duration, 423 were returned but 359 were found usable. An instrument comprising of six-item measures adapted from De Vries et al. (2006) was used to gauge knowledge sharing behavior. Data were analyzed using SPSS version 14.0. Non-response biases were analyzed by comparing early responders and late responders using independent sample ttest. The results revealed that the responses 
were free from non-response biases. Factor analysis was then executed on the items measuring knowledge sharing and the findings showed that all items were cleanly loaded into one single factor. The reliability analysis performed also showed that items measuring knowledge sharing recorded Cronbach alpha value of 0.907 suggesting that the instrument used in the study was highly reliable.

\section{Findings}

\section{Demographic Profile}

Table 1 presents the demographic profiles of the research samples. Between male and female, the former seemed to outnumbered the later with $54.9 \%$ as opposed to $45.1 \%$. Age group between 31 and 35 was most dominant and contributed to $29.5 \%$ of the sample. In terms of qualifications, 284 respondents indicated to have gotten first degree while 23 indicated to have obtained Masters. 306 respondents indicated as holding executives posts while 53 were holding middle management post. The average length of service was 7.62 while intranet experience recorded a mean of 6.92 .

\section{Knowledge Sharing Behavior between Gender}

Table 2 depicts the descriptive profile of knowledge sharing behavior between male and female. The results showed that the mean score for both gender is around 5, suggesting that there is not much difference for both male and female in terms of knowledge sharing behavior. To further ascertain this finding, an independent sample $t$ test was performed and the results evidently showed that the $p$ value is 0.616 which is greater than 0.05 , hence indicates that there is no significant difference on knowledge sharing between both gender.

Table 1. Demographic Profiles of Respondents

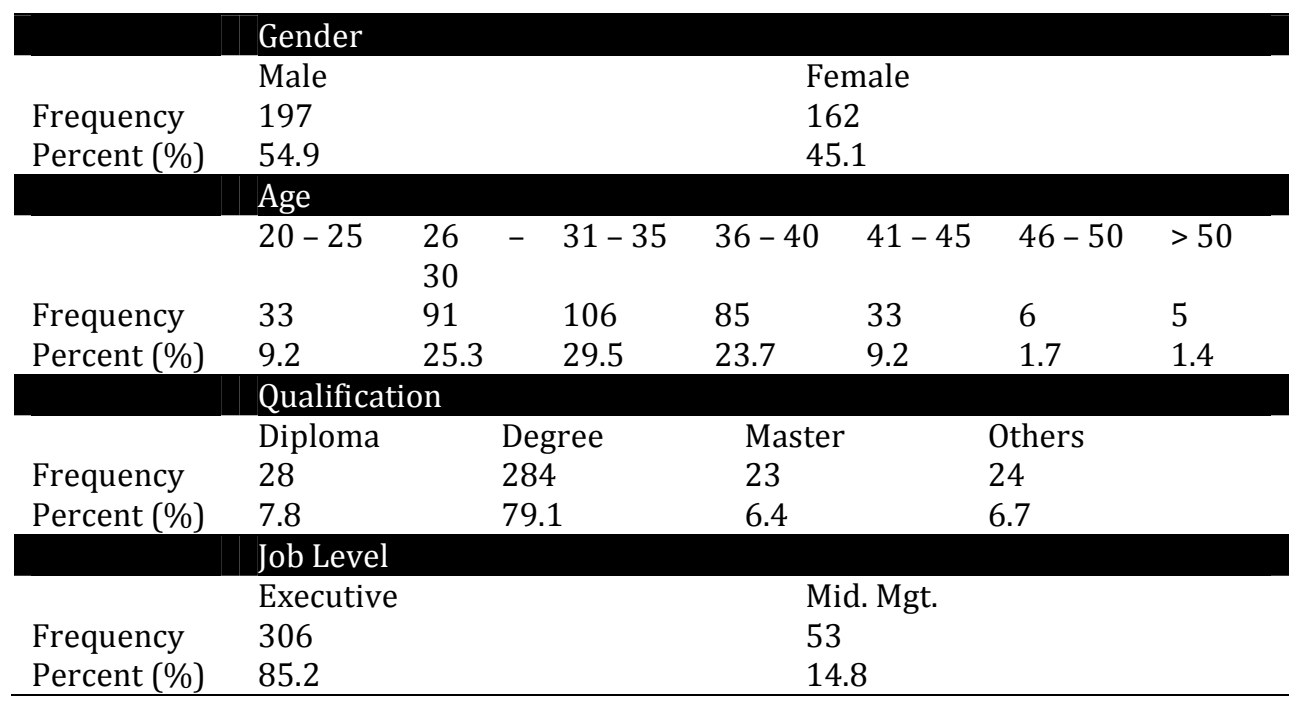

Table 2. Descriptive Profile of Knowledge Sharing Behavior between Male and Female

\begin{tabular}{ll|ll|ll} 
& Gender & $\mathrm{N}$ & Mean & $\begin{array}{l}\text { Std. } \\
\text { Deviation }\end{array}$ & $\begin{array}{l}\text { Std. Error } \\
\text { Mean }\end{array}$ \\
\hline \multirow{2}{*}{ Knowledge_Sharing } & Male & 197 & 5.0000 & 1.08849 & 0.07755 \\
\cline { 2 - 7 } & Female & 162 & 5.0586 & 1.11803 & 0.08784 \\
\hline
\end{tabular}




\section{Different Age Group of Users}

To investigate whether there are significant differences across different age groups in terms of knowledge sharing behavior, ANOVA test was performed. The results showed that the $\mathrm{p}$ value is greater than 0.05 , hence, suggesting that there is significant difference on knowledge sharing among different age group suggesting. Further analysis was performed using Scheffe test and the result is shown in Table 3.

Table 3. Results of Scheefe Test across Age Groups

\begin{tabular}{llll}
\hline & \multicolumn{3}{c}{ Subset for alpha =.05 } \\
Between 20 and 25 & N & 1 & 2 \\
Between 26 and 30 & 90 & 4.1313 & \\
Between 31 and 35 & 107 & 4.7037 & 4.7037 \\
Between 36 and 40 & 85 & 5.1121 & 5.1121 \\
Between 41 and 45 & 33 & 5.3471 & 5.3471 \\
Between 46 and 50 & 6 & 5.4646 & 5.4646 \\
Between 51 and 55 & 5 & & 5.6667 \\
\hline Sig. & .052 & 5.8000 \\
Means for groups in homogeneous subsets are displayed. \\
a Uses Harmonic Mean Sample Size= 15.234. \\
$b$ The group sizes are unequal. The harmonic mean of the group sizes is used. Type I error \\
levels are not guaranteed.
\end{tabular}

\section{Knowledge Sharing Behavior between Managers and Non-managers}

Table 4 depicts the descriptive profile of knowledge sharing behavior between executive and middle managers. The mean value of knowledge sharing for middle managers seems to be higher as compared to the executives. However, to further ascertain whether this difference is significant, an independent sample $t$ test was performed. Evidently, the results showed that the $\mathrm{p}$ value is smaller than 0.05 , thus, implying that the difference is significant.

Table 4. Descriptive Profile of Knowledge Sharing between Executive and Middle Managers

\begin{tabular}{|c|c|c|c|c|c|}
\hline & Job Level & $\mathrm{N}$ & Mean & $\begin{array}{l}\text { Std. } \\
\text { Deviation }\end{array}$ & $\begin{array}{ll}\text { Std. } & \text { Error } \\
\text { Mean } & \end{array}$ \\
\hline \multirow[t]{2}{*}{ Knowledge_Sharing } & Executive & 306 & 4.9297 & 1.04326 & 0.05964 \\
\hline & $\begin{array}{l}\text { Middle } \\
\text { Management }\end{array}$ & 53 & 5.5849 & 1.25899 & 0.17294 \\
\hline
\end{tabular}

\section{Length of Service and Knowledge Sharing Behavior}

Table 5 and 6 present the results of linear regression between length of service and knowledge sharing behavior. It was noted that the value of Pearson's $r=0.318$ while $\mathrm{R}^{2}$
$=0.101$, with $\mathrm{F}(1,357)=40.213$ and $\mathrm{p}<$ 0.001. These figures show that low correlation but weak relationship subsist and that length of service single-handedly explained $10.1 \%$ of the variation of knowledge sharing behavior. 
Table 5. Summary of Regression Model between Length of Service and Knowledge Sharing Behavior

\begin{tabular}{l|ll|ll|} 
Model & $\mathrm{R}$ & R Square & $\begin{array}{l}\text { Adjusted R } \\
\text { Square }\end{array}$ & $\begin{array}{l}\text { Std. Error of } \\
\text { the Estimate }\end{array}$ \\
\hline 1 & $.318(\mathrm{a})$ & .101 & .099 & 1.04501 \\
\hline \multicolumn{3}{r}{ a Predictors: (Constant), LgthService }
\end{tabular}

Table 6. Coefficient for Regression Model between Length of Service and Knowledge Sharing Behavior

\begin{tabular}{|c|c|c|c|c|c|c|}
\hline \multirow[b]{2}{*}{ Model } & & \multicolumn{2}{|c|}{$\begin{array}{l}\text { Unstandardized } \\
\text { Coefficients }\end{array}$} & \multirow{2}{*}{$\begin{array}{l}\text { Standardized } \\
\text { Coefficients } \\
\text { Beta }\end{array}$} & \multirow[b]{2}{*}{$\mathrm{t}$} & \multirow[b]{2}{*}{ Sig. } \\
\hline & & B & Std. Error & & & \\
\hline \multirow[t]{2}{*}{1} & (Constant) & 4.486 & .102 & & 44.196 & .000 \\
\hline & LgthService & .071 & .011 & .318 & 6.341 & .000 \\
\hline
\end{tabular}

a Dependent Variable: Knowledge_Sharing

\section{Internet Experience and Knowledge Sharing Behavior}

Table 7 and 8 depict the results of linear regression between length of service and knowledge sharing behavior. Tt was noted that the value of Pearson's $r=0.445$ while $\mathrm{R}^{2}$
$=0.198$, with $\mathrm{F}(1,357)=87.995$ and $\mathrm{p}<$ 0.001. These figures show that low correlation but moderate relationship exist and that intranet experience singularly explained $19.8 \%$ of the variation of knowledge sharing behavior.

Table 7. Summary of Regression Model between Intranet Experience and Knowledge Sharing Behavior

\begin{tabular}{|c|c|c|c|c|}
\hline Model & $\mathrm{R}$ & R Square & $\begin{array}{l}\text { Adjusted R } \\
\text { Square }\end{array}$ & $\begin{array}{l}\text { Std. Error of } \\
\text { the Estimate }\end{array}$ \\
\hline 1 & $.445(a)$ & .198 & .195 & .98731 \\
\hline
\end{tabular}

a Predictors: (Constant), IntranetExp

Table 8. Coefficient for Regression Model between Intranet Experience and Knowledge Sharing Behavior

\begin{tabular}{|l|lllll|l|}
\hline & & \multicolumn{3}{|c|}{$\begin{array}{l}\text { Unstandardized } \\
\text { Coefficients }\end{array}$} & $\begin{array}{l}\text { Standardized } \\
\text { Coefficients }\end{array}$ & \\
Model & & $\mathrm{B}$ & Std. Error & Beta & $\mathrm{T}$ & Sig. \\
\hline 1 & $\begin{array}{l}\text { (Constant) } \\
\text { IntranetEx } \\
\mathrm{p}\end{array}$ & 3.910 & .130 & & 30.105 & .000 \\
& .161 & .017 & .445 & 9.381 & .000 \\
\hline
\end{tabular}

a Dependent Variable: Knowledge_Sharing 


\section{Discussion}

Utilizing intranet for knowledge-sharing purposes has been vastly discussed both in IS and KM literature. Typically, knowledgesharing activities entail two main activities namely; knowledge donating and knowledge collecting. With the availability of the intranet, these two activities have become more conveniently practiced. Users at any time of the day and at their own will can easily record or donate whatever knowledge that could be relevant and beneficial to others. On the other hand, users can also freely retrieve or collect knowledge pertinent to their needs from the intranet, thereafter assimilating them for usage or application. As this study had evidently showed that intranet was utilized for knowledge sharing purposes, findings by earlier studies are therefore, affirmed (Stenmark, 2002; Lichtenstein et al., 2004).

Numerous studies have consistently shown that individual characteristics such as demographic profile and other traits such as job level, length of service and internet experience are predictors of IT or IS usage behavior. While previous studies have found gender differences in terms of IT usage behavior (Gefen and Straub, 1997; Gardner, 2004) this study has, however, discovered contradicting result. The possible explanation could be that, unlike previous studies, IT usage behavior in this study was measured in terms of their knowledge sharing via the intranet. Furthermore, the job nature of these respondents, which are identical irrespective of their gender, could be also another reason.

This study has categorized the age of the respondents into 7 groups. As noted in the previous section, other than those aged between 20 and 25, other age groups displayed an almost identical pattern in terms of their knowledge sharing behavior. Compared to other age groups, respondents aged between 20 and 25 have the least number of experience working in the organizations. Being more junior, surely they have fewer companions or cohort in the workplace and that would certainly limit their knowledge sharing activities.

With regards to knowledge sharing behavior in terms of job level, this study has found there is a significant difference between managers and non-manager (executives). However, this finding has to be interpreted with cautious considering uneven number of respondents between the two job levels. Nevertheless, it was clear that the overall mean for the middle manager is greater than the executives which could be attributed by the fact that the job nature of the manager requires them to repetitively share work knowledge especially with their subordinates. Other possible explanation would be that managers are the centers or nucleus for subordinates in their job reporting. In the process, these subordinates would be likely to share their knowledge and experience with their superior. Previous studies indicate that length of service has mixed results as a determinant of IS usage behavior. For instance, Burkhardt (1994) discovered negative correlation between length of service and computer usage while Liao and Landry (2000) found that staff with longer length of service tend to perceive the newly implemented IS as being very useful, which in turn became the strong predictor to the IS acceptance. Apparently, in terms of knowledge sharing behavior, the findings of this study is consistent with that of Liao and Landry (2000). Employees with longer length of service usually have better understanding of organizational processes and operations, as well as better involvement and contribution during the implementation of the intranet. Hence, these employees would perhaps perceive the intranet as being very useful, which in turn heightens usage level which includes the purpose of knowledge sharing.

In investigating individual IS utilizaton behavior, many researchers had also studied the effect of computer or internet experience. Evidently, many of these studies had found a strong support on the assertion that 
computer or internet experience is a predictor of IS usage behavior (Igbaria and Iivari, 1995; Hubona and Geitz, 1997; Alshare et al., 2004). In the context of intranet usage study, Chang (2004) also discovered similar finding, which is also confirmed by the findings of this study. Intranet is almost similar to internet and the only difference is on the breadth and scope of its user coverage. Therefore, users who are already familiar with the internet and webapplications will find the intranet is just as convenient to the internet which in turn promote their usage level not only for information searching but also for knowledge sharing.

\section{Conclusion}

The conduct of this study has been to investigate the demographic profiles of knowledge sharing behavior in an intranet computing environment among executive staffs in selected Malaysian. The study has provided empirical evidence on the importance of intranet as an important knowledge sharing tool in the workplace. Despite the success of accomplishing the research objectives, this study is also subject to a number of limitations which is mainly associated with adopted research method. Firstly, the chosen respondents were those holding executive level positions or higher, and users of the lower level positions were omitted. Therefore, future research should consider adopting every intranet user irrespective of their job level as respondents. As such, differences and comparisons can be made between job-level and status of intranet utilization. Secondly, the chosen companies were of those of GLC only, hence other public and fully private companies were excluded. Among government organizations, little is really known about the intranet utilization behavior among civil servants. Apparently, it is worth venturing into research that explores the status of intranet utilization in government agencies especially when these organizations are steadily geared towards paperless office or e- government. Equally appealing would be investigating the status of intranet utilization in fully private companies such as those from banking or manufacturing industries. Undeniably, the situation and atmosphere in these companies are totally different as those from the GLC or government as they are more tailored towards cost-saving and profit making. Apparently, this situation warrants research undertakings. Thirdly, the perceptual measures employed in the survey instrument are subject to individual interpretation and understanding. Hence, instead of using self-reported measures for measuring intranet usage for knowledge sharing, a more accurate approach would be installing software-tracking systems onto the intranet that would both monitor and record usage. However, such approached would be quite difficult unless permission and access are granted by the organization's intranet. Also, objective measures as a substitute to perceptual measures would also provide more accurate measurement.

\section{References}

Al-Gharbi, K. \& Atturki, S. M. (2001). "Factors Influencing the Infusion of Intranet in Knowledge Management in Developing Countries Organizations," Proceedings of the 10th International Conference on Management of Technology, Lausanne, Switzerland.

Alshare, K., Grandon, E. \& Miller, D. (2004). "Antecedents of Computer Technology Usage: Considerations of the Technology Acceptance Model in the Academic Environment," Journal of Computing Sciences in Colleges, 19(4), 164180.

Burkhardt, M. E. (1994). "Social Interaction Effects Following a Technological Change: A Longitudinal Investigation," The Academy of Management Journal, 37, 869-896.

Butler, P., Cales, R.\& Petersen, J. (1997). Using Microsoft Commercial Internet System, Indianapolis, Que Publishing. 
Casselberry, R. et al. (1996). Running a Perfect Intranet, Indianapolis, Que Publishing.

Chang, P. V. (2004). "The Validity of an Extended Technology Acceptance Model (TAM) for Predicting Intranet/Portal Usage," Unpublished masters dissertation, University of North Carolina at Chapel Hill, USA.

Damsgaard, J. \& Scheepers, R. (2001). “Using Intranet Technology to Foster Organizational Knowledge Creation," Global Co-Operation in the New Millennium, Proceedings of the 9th European Conference on Information Systems (ECIS2001), Bled, Slovenia

Davis F. D., Bagozzi, R. P. \& Warshaw, P.R. (1989). "User Acceptance of Computer Technology: A Comparison of Two Theoretical Models," Management Science, 35 (8), 982-1003.

De Vries, R. E., Den Hooff, B. V. \& De Ridder, J. A. (2006). "Explaining Knowledge Sharing: The Role of Team Communication Styles, Job Satisfactions and Communication Beliefs," Communications Research, 33(2), 115-135.

Dingsoyr, T. \& Royrvik, E. (2003). "An Empirical Study of an Informal Knowledge Repository in a Medium-Sized Software Consulting Company," Proceedings of the 25th International Conference on Software Engineering (ICSE2003), Portland, Oregon, USA.

Eder, L. B. \& Igbaria, M. (2001). "Determinants of Intranet Diffusion and Infusion," Omega, 29 (3), 233-242

Gardner, C. \& Amoroso, D. L. (2004). "Development of an Instrument to Measure the Acceptance of Internet Technology by Consumers," Proceedings of the 37th Hawaii International Conference on System Sciences $-2004$.

Gefen, D. \& Straub, D. W. (1997). "Gender Differences in the Perception and Use of EMail: An Extension to the Technology Acceptance Model," MIS Quarterly, 389-400.
Golden, W. \& Hughes, M. (2001). "Business Process Re-Engineering Using Intranets: A New Beginning," Proceedings of the 14th Bled Electronic Commerce Conference, Bled, Slovenia.

Hall, H. (2004). "The Intranet as Actor: The Role of the Intranet in Knowledge Sharing," Proceedings of the International Workshop on Understanding Sociotechnical Action (USTA2004), Edinburgh, Scotland, 109-111.

Hinrichs, R. J. (1997). "Intranets: What's the Bottom Line?," Mountain View, CA, Sun Microsystems Press.

Holden, T. (2003). "Understanding the Dimensions of Knowledge Sharing: Designing an Intranet to Improve Operational Performance in a Multinational Corporation," International Journal of Electronic Business. $1(2), 118-139$.

Horton, R. P., Buck, T., Waterson, P. E. \& Clegg, C. W. (2001). "Explaining Intranet Use with Technology Acceptance Model," Journal of Information Technology, 16, 237-249.

Hubona, G. S. \& Geitz, S. (1997). "External Variables, Beliefs, Attitudes and Information Technology Behavior," Proceedings of the 30th Annual Hawaii International Conference on System Sciences (HICSS97), Hawaii, USA.

Igbaria, M. \& Iivari, J. (1995). "The Effects of Self-Efficacy on Computer Usage," Omega, 23(6), 587-605.

Jeyaraj, A., Rottman, J. W., \& Lacity, M. C. (2006). "A Review of Predictors, Linkages and Biases in IT Innovation Adoption Research," Journal of Information Technology, $21,1-23$.

Karlsbjerg, J. \& Damsgaard, J. (2001). "Make or Buy - A Taxonomy of Intranet Implementations Strategies," Proceedings of the 9th European Conference on Information Systems (ECIS2001), Bled, Slovenia. 
Liao, Z. \& Landry, R. (2000). "An Empirical Study on Organizational Acceptance of New Information Systems in a Commercial Bank Environment," Proceedings of the 33rd Hawaii International Conference on System Science (HICSS2000), Hawaii, USA.

Lichtenstein, S., Hunter, A. \& Mustard, J. (2004). "Utilization of Intranets for Knowledge Sharing: A Socio-Technical Study," Proceedings of the 15th Australasian Conference on Information Systems (ACIS2004), Tasmania, Australia.

Lyntinen, K., Rose, G. \& Welke, R. (1998). "The Brave New World of Development in the Internetwork Computing Architecture (Internca) or How Distributed Computing Platforms Will Change Systems Development," Information Systems Journal, 8, 241-253.

Newell, S., Scarbrough, H., Swan, J. \& Hislop, D. (1999). "Intranets and Knowledge Management:

Complex Processes and Ironic Outcomes," Proceedings of the 32nd Hawaii International Conference on System Sciences (HICSS1999), Hawaii, USA.

Panteli, N., Tsiourva, I. \& Modelley, S. (2005). "Intra-organizational Connectivity and Interactivity with Intranets: The Case of Pharmaceutical Company," Working paper, University of Bath, UK.

Rogers, E. M. (1983). Diffusion of Innovations. New York: Free Press.

Ruppel, C. P. \& Harrington, S. J. (2001). "Sharing Knowledge through Intranets: An Analysis of the Organizational Culture Leading to Intranet Adoption and Use," IEEE Transactions on Professional Communications, 44(1), 37.

Sarkar, R. J. \& Bandyopadhyay, S. (2002). "Developing an Intranet-Based Knowledge Management Framework in a Consulting Firm: A Conceptual Model and its Implementation," Workshop on Knowledge
Management and Organizational Memories (ECAI02), Lyon, France.

Scheepers, R. (1999). "Intranet implementation: Influences, Challenges and Role Players," Unpublished doctoral dissertation. Aalborg University, Denmark.

Scott, J. E. (1998). “Organizational Knowledge and Intranet," Decision Support Systems, 23, 3-17.

Shilakes, C., \& Tylman, J. (1998). 'Enterprise Information Portals,' New York, Merrill Lynch, Inc.

Skok, W. \& Kamanovitch, C. (2005). "Evaluating the Role And Effectiveness Of An Intranet In Facilitating Knowledge Management: A Case Study At Surrey County Council," Information \& Management, 42, 731-744.

Slevin, J. (2000). The Internet and Society, Cambridge, Polity Press.

Stanek, W. R. (1997). Web Publishing: Professional Reference Edition Unleashed, Indianapolis, Sams.net Publishing.

Stenmark, D. (1999a) "Using Intranet Agents to Capture Tacit Knowledge," Proceedings of World Conference on the WWW and Internet, (WebNet99), Honolulu, Hawaii, USA, 1000 1005.

Stenmark, D. (2002). "Information vs. Knowledge: The Role of Intranets in Knowledge Management," Proceedings of the 35th Hawaii International Conference on System Sciences (HICSS2002), Hawaii, USA.

Stenmark, D. (2005c). "Knowledge Sharing on a Corporate Intranet: Effects of Re-Instating Web Authoring Capabilities," Proceedings of the 13th European Conference on Information Systems (ECIS 2005), Regensburg, Germany.

Stenmark, D. (2005e). "Knowledge Sharing through Increased User Participation on a 
11 Journal of Organizational Knowledge Management

Corporate Intranet," Proceedings of the 6th European Conference on Organizational Knowledge, Learning, and Capabilities (OKLC2005), Bentley College, Massachusetts, USA.

Stoddart, L. (2001). "Managing Intranets to Encourage Knowledge Sharing: Opportunities and Constraints", Online Information Review, 25(1).

Venkatesh, V., Morris, M. G., Davis, G. B. \& Davis, F. D. (2003). "User Acceptance of Information Technology: Toward a Unified View," MIS Quarterly, 27(3), 425-478.

Weitzel, D. \& Hallahan, K. (2003). "Organizational Adoption of an Intranet-
Based Performance Reporting System: A Test Of Rogers' Model of Innovation," In the New Technologies in Organizational Contexts Communications and Technology Division, International Communication Association, San Diego, 26th May 2003 [On-line] [Retrieved 7 June, 2005]

http://lamar.colostate.edu/ pr/adoptionepo wer.doc

Zachman, J. A. (1987). “A Framework for Systems Architecture," IBM Systems Journal, 26

(3),

276

292.

Zimmerman, S. \& Evans, T. (1996). Building an Intranet with Windows NT 4. Indianapolis, Sam.net Publishing. 